\title{
EL CONCEPTO Y LA VERDAD EN HEIDEGGER Y ZUBIRI (DIÁlOGO CON TEORÍAS DE LA ABSTRACCIÓN Y CON LA TEORÍA HERMENÉUTICA)
}

\author{
VÍCTOR M. TIRADO SAN JUAN \\ Universidad Eclesiástica San Dámaso y Universidad Pontificia de Salamanca
}

\begin{abstract}
RESUMEN: El artículo expone y analiza la crítica de Heidegger al conceptismo de la metafísica clásica y a su teoría de la abstracción, que se fundarían según el pensador alemán en el desgaste del lenguaje y el uso impropio que de él se hace en la metafísica clásica, tergiversando y ocultando el auténtico sentido del pensamiento y del ser en lo genuinamente griego. Sobre esta base Heidegger postula la insuficiencia del concepto y de lo lógico a la vez que la necesidad de un método hermenéutico. El artículo señala los puntos de coincidencia de esta perspectiva con la crítica zubiriana al idealismo y al conceptismo. Teniendo en cuenta todo ello, se trata de mostrar, no obstante, que son posibles conceptos descriptivos capaces de adecuarse a lo real, lo que supone en la realidad misma un momento sustancial de presencia de una cierta permanencia (la crítica a la metafísica de la presencia de Heidegger tampoco sería aceptable). Se hace una exposición y análisis de la magnífica crítica de Zubiri a la teoría clásica de la abstracción intentando conciliarla, empero, con la validez de los conceptos descriptivos y con momentos universales de la realidad. La tesis de fondo es que la filosofía primera no puede reducirse a hermenéutica.
\end{abstract}

PALABRAS CLAVE: Zubiri, Heidegger, abstracción, concepto, conceptismo, hermenéutica, filoosfía primera, esencia.

\section{The concept and truth in Heidegger and Zubiri (Dialogue with theories of abstraction and the hermeneutics)}

\begin{abstract}
This article ses out and analyses Heidegger's criticism against the conceptism from classical metaphysics and its abstraction theory, which according to the thought of the German thinker should be both founded in language's wear and in the unsuitable use that classical metaphysics do from it distorting and hiding the very genuine sense from Greek thought and being in the Greek culture. Heidegger postulates the insufficiency of the concept and of the logic while he proposes the need of an hermeneutical method. The article points out the overlapping perspectives between Heidegger's proposal and Zubiri criticism against idealism and conceptism. Taking into account all that, the author will show, that they are possible descriptive concepts, which are able to adapt to the real. This fact implies there is a substantial moment in reality, which remain present during a certain time (so it implies that Heidegger criticism again the «metaphysic of the presence» is neither acceptable). The article explains and analyses the excellent Zubiri criticism against the classical theory of abstraction, by trying to harmonize it with the validity of the descriptive concepts and with universal moments of the reality. The main thesis is that first philosophy could not be reduced to hermeneutic.
\end{abstract}

KEY WORDS: Zubiri, Heidegger, abstraction, concepto, conceptism, hermeneutic, first philosophy, essence. 


\section{INTRODUCCIÓN}

El lugar común de la filosofía hermenéutica, que es filosofía existencialista, es la crítica a la metafísica clásica, a la que se considera superada. Ello guarda relación esencial con el problema de la verdad, y así, con la cuestión del concepto, o si se quiere, de la capacidad de la mente humana para acceder a la verdad (a la realidad) a través del concepto. Heidegger, retomando la línea de pensamiento de Nietzsche y después de Dilthey, imprime un giro hermenéutico a la fenomenología, incorporándose a las corrientes que desde el inicio de la modernidad vinieron haciendo una crítica radical de la metafísica clásica. Es en este contexto que el pensador alemán ataca el «conceptualismo». La cuestión es decisiva en Zubiri, quien ha propuesto, a la vez que un pensamiento metafísico, es decir, un pensamiento que pretende acceder a lo real y a lo trascendental de la realidad, una crítica de la inteligencia concipiente. En el planteamiento zubiriano luchan simultáneamente la fenomenología de raíz husserliana - que vuelve a conectar el pensamiento contemporáneo con la tradición metafísica occidental - y la fenomenología de raíz heideggeriana, que, a pesar de bucear en la tradición, da, según decimos, la metafísica por saldada incorporando motivos "existencialistas», hermenéuticos y nietzscheanos.

\section{Verdad y CONCEPTO EN Heidegger}

En «Tarea y presente de la filosofía de la religión» ${ }^{1}$ Heidegger dice:

«Si aceptamos atender específicamente a la religiosidad del cristianismo primitivo, hay que constatar que se trata de un Factum histórico. Si concebimos la estructura filosófica como un ámbito preciso y delimitado — por ejemplo, como conciencia-, entonces el factum de la religiosidad del cristianismo primitivo se convierte en caso particular, esto es, en ejemplo dentro de una esfera de posibilidades, de tipos de posibles formas de religiosidad (...) De este modo los tipos religiosos históricos son situados en una multiplicidad de posibilidades. Constituyen un material a partir del cual se crea; constituyen así una multiplicidad supratemporal».

Heidegger alude a términos tales como «caso particular», «tipo», «ejemplo», «multiplicidad de posibilidades» $\mathrm{y}$ «multiplicidad supratemporal», que yo he señalado con letra cursiva. Son conceptos de la tradición metafísica clásica, que el pensador alemán va a poner en cuestión. En este sentido, el error de la filosofía de la religión residiría, precisamente, en el uso de esta estructura metodológica eidética y abstractiva para comprender una determinada religión histórica, como si ella fuera un «caso particular» de un «tipo» o paradigma universal genérico y supratemporal conceptualmente definido.

1 Heidegger, M. (1995), Phänomenologie des religiösen Lebens, GW. Bd. 60. Frankfurt: V. Klostermann, p. 75 (la traducción es siempre mía). 
Más adelante, en el párrafo veintidós de la misma obra leemos en torno al método fenomenológico aplicado a la religión, lo siguiente:

«Esquemáticamente los pasos para la explicación fenomenológica son los siguientes: 1) Puesto que el fenómeno fundamental es la experiencia vital fáctica y ésta es histórica, entonces lo primero es determinar la conexión fenomenológica como situación histórica en el modo de objetividad histórica prefenomenológica y en todo caso a partir de motivos prefenomenológicos. 2) Hay que alcanzar la realización de la situación histórica del fenómeno. Y para ello hay que: a) caracterizar la multiplicidad que tiene lugar en la situación, sin que se decida sobre la verdadera conexión (articulación de la multiplicidad-situación); b) alcanzar la precisa situación de la multiplicidad; c) sacar a la luz el sentido primario o arcóntico (dominante). A partir de ahí, d) alcanzar la conexión fenoménica. Y a todo esto hay que añadir: 3) el comportamiento fundamental de la experiencia vital personal del contemplador (fenomenólogo) debe ser desconectado. 4) La contemplación se dirige al fenómeno histórico, pero no deja en ello lo decisivo. La explicación sube progresivamente de nivel, cada vez se hace más individual, cada vez se aproxima más a la auténtica facticidad histórica»

Y una vez descrito este complejo método, Heidegger señala tres dificultades: La primera dificultad consiste en:

«la exposición mediante el lenguaje: El lenguaje de la contemplación objetiva [Sachbetrachtung] no es originario. Hay ya en la experiencia vital fáctica una conceptualización más originaria, sólo a partir de la cual tiene su procedencia la conceptualidad objetiva que nos es habitual (...) Simplemente no es posible alcanzar conceptos autoevidentes. (La pregunta acerca de los conceptos filosóficos ya no se ha vuelto a plantear desde Sócrates) (..) Y no se puede, sin embargo, tildar la vida de "irracional", sin haberse aclarado sobre el sentido de irracionalidad. No se comprende ningún explicando hasta que no se ha completado su señalada conexión de sentido. Y esta complexión misma pertenece al concepto del fenómeno. El concepto filosófico tiene una estructura que es incomparable con la del concepto de cosa»

La segunda dificultad hace referencia a la intrafección o endopatía. Nosotros la obviamos aquí, porque no es nuestro tema.

La tercera dificultad apunta ya al problema mismo de la abstracción en el marco de la explicación, y por tanto del concepto:

«La cuestión de la explicación misma: (...) lo propio de la abstracción teorética según actitud es que se aprehende lo abstraído como momento de una región objetiva, de modo que así se gana la determinación fundamental de la región. Lo abstraído se sigue considerando al margen de aquello de lo que es abstraído; el fundamento de la abstracción es indiferente. La abstracción en tanto que tal, el tránsito del fundamentum abstractionis al abstraer no llega a una empatía [Mit-erfahrung]. De manera distinta ocurre en la explicación: cuando en la explicación se explicitan determinados momentos, aquellos momentos de sentido a los que no alcanza la explicación no son simplemente echados a un lado, sino que el "cómo" de su penetración en lo ahora explicitado o en la dirección de sentido comprendida en la explicación está también 
codeterminada por la explicación misma. Y aquí cabría preguntar: ¿es posible considerar con el sentido de referencia [Bezugsinn] simultáneamente el "qué" (el contenido), aquél al que se refiere, y a la vez el cómo de la realización? Esta objeción es comprensible. Se comprenden las tres direcciones de sentido. La realización de la explicación no es ninguna consecuencia sedimentada de actos, de determinaciones aprehensivas. Tan sólo debe alcanzarse en una conexión vital concreta. Así se conllevan también direcciones de sentido "no vistas"”

Lo que nos concierne de estas apreciaciones de Heidegger son, de nuevo, sus objeciones a la pretensión de una descripción conceptiva de un fenómeno histórico como es la religión (una religión concreta), pero que podrían generalizarse a la conceptuación en general. La primera objeción creo que apunta a una supuesta imposibilidad de acceder a conceptos originarios («autoevidentes», dice Heidegger). Cualquier concepto que utilicemos para describir una realidad remite a un uso anterior en el mundo de la vida (Lebenswelt) — si es que queremos utilizar esta categoría de Husserl.- Una genealogía infinita haría opaco cualquier concepto que quisiésemos utilizar para llegar a comprender un determinado acontecimiento individual histórico. Y en relación a la abstracción añade una nueva dificultad, que nos interesa mucho retener. El problema de los conceptos descriptivos universales es que son el resultado de un proceso abstractivo, y éste consiste, justamente, en abandonar lo individual-real, que es necesariamente "histórico» (aquí, ahora, en un sentido muy general equivalente a «temporal»), para elevarse a un contenido abstracto (literalmente Heidegger dice: «lo abstraído se sigue considerando al margen de aquello de lo que es abstraído»). De esta manera, quién trata de hacer ciencia con este método vive desplazado del ámbito originario e intuitivo, real, moviéndose por el contrario en una esfera puramente conceptual («región objetiva», dice Heidegger) vacía de intuición real; es decir, en términos de Zubiri, acabaría moviéndose en una inteligencia meramente conceptiva, en lugar de en una inteligencia sentiente, pues es imposible — viene a decir Heidegger — alcanzar la complexión de adecuación entre el concepto y el contenido intuitivo.

En la lección de Introducción a la metafísica impartida en el semestre de verano de 1935 en Freiburg ${ }^{2}$, Heidegger retoma su tradicional tesis de que la filosofía cristiana pervirtió el lenguaje filosófico griego, y así, el tema del lenguaje originario (desvelador) frente al lenguaje sucedáneo (ocultador). Empero, lo que nos interesa en este contexto es la crítica que hace a la estructura lógica del lenguaje, porque en ella aparece la posición de Heidegger en relación a los conceptos y a la abstracción. De lo que se trata es de si la lógica condiciona todo pensar o, a la inversa, el modo de pensar condiciona la lógica. En ese caso, ¿en qué consistiría ese pensar pre-lógico, ese pensar an-árquico más originario que la lógica? Dice Heidegger:

2 Heidegger, M. (1983), Einführung in die Metaphysik. Gesammtausgabe; II. Abteilung, Vorlesungen 1923-1944, Bd 40. Frankfurt am Mein, Vittorio Klostermann (cito por la traducción española: Introducción a la metafísica (1960). Buenos Aires: Ed. Nova. 
(63) «es absolutamente imposible decidir con tal seguridad si la lógica y las reglas fundamentales de la misma pueden entregar en general el criterio de la pregunta por el ente como tal. Podría ocurrir lo contrario: que la Lógica íntegra, profesada por nosotros, y tratada como un regalo del cielo, se fundara sobre una determinada respuesta a la pregunta por el ente; por tanto, podría suceder que todo pensar que siga simplemente las leyes del pensamiento de la lógica habitual sea de antemano incapaz de comprender, desde sí mismo, la pregunta por el ente, y menos aún de desplegarla realmente y oponerle una propia respuesta»

Esta cuestión es decisiva desde el origen de la filosofía. Está en conexión directa con el problema de la sustancia, pues la doctrina sofística del cambio continuo impide que ningún ser permanezca idéntico en el tiempo, y así, al no haber identidad, no hay principio de no-contradicción ${ }^{3}$. Igualmente está en conexión directa con el giro hermenéutico y fenomenológico producido en el pensamiento contemporáneo: el lenguaje lógico pierde su relevancia frente a la fenomenología genética en Husserl (la «lógica formal» se subordina a la «lógica trascendental») y frente al lenguaje ordinario en el giro lingüístico, también frente a la genealogía infinita de Nietzsche-Derrida-Heidegger-Ricoeur, etc. No hay un lenguaje propio de conceptos, sino que todo son metáforas, y metáforas de metáforas... en la historia infinita del ser.

Y continúa Heidegger:

«Cuando se invoca el principio de contradicción y la Lógica en general para probar que todo pensar y hablar acerca de la nada es contradictorio, y por eso mismo, sin sentido, sólo se logra, en verdad, una apariencia de rigor y cientificidad. "La Lógica" rige en estos casos como un tribunal asegurado desde la eternidad, de cuyas atribuciones, naturalmente, ningún hombre razonable dudaría (...) Quien hable contra la lógica, tácita o expresamente, se hará sospechoso de arbitrariedad (...) quien pretenda hablar de la nada no podrá

3 Platón, Teeteto, [152 d 3] «que ninguna cosa tiene un ser único en sí misma y por sí misma y que no podrías darle ninguna denominación justa, ni decir que es de una clase determinada. Al contrario, si la llamas grande, resulta que también parece pequeña y, si dices que es pesada, también parece ligera, y así ocurriría con todo, ya que no hay cosa que tenga un ser único, ni que sea algo determinado o de una clase cualquiera. Ciertamente, todo lo que decimos que es, está en proceso de llegar a ser, a consecuencia de la traslación, del movimiento y de la mezcla de unas cosas con otras, por lo cual no las denominamos correctamente. Efectivamente, nada es jamás, sino que está siempre en proceso de llegar a ser».

F. Inciarte \& A. Llano (2007), Metafísica después de la metafísica. Ed. Cristiandad, Madrid. Los autores creen que la deconstrucción propuesta por Derrida para el final de la metafísica remite a la discusión de Aristóteles sobre el principio de no-contradicción en el libro IV de la Metafísica, e igual que pasaba entonces con los críticos de la filosofía: (30-31) «se patentiza cómo las diversas contraposiciones que los críticos de la metafísica pretenden disolver remiten, en último término, a distinciones entre lo verdadero y lo falso. La postura radicalmente antimetafísica acaba casi siempre por proponer una nivelación de la diferencia entre lo verdadero y lo falso, de modo [/] que o bien todo fuera verdadero o bien todo fuera falso (...) Protágoras y Nietzsche son los dos representantes extremos de estas posturas, reeditadas de maneras muy sofisticadas en el postestructuralismo y deconstruccionismo del siglo xx». 
ser, necesariamente, un científico. Pero sigue siendo una gran desdicha creer que el pensar de la ciencia sea el único y peculiar pensamiento estricto, como si sólo él se pudiera y tuviera que poner como criterio del pensar filosófico. Sin embargo, la situación real es la opuesta. Todo pensar científico es una forma derivada y, como tal, condensada del pensamiento filosófico. La filosofía jamás nace de y por la ciencia (...) se haya en un dominio y ocupa un puesto de la existencia espiritual completamente diferente. Ella y su pensar están en la misma ordenación que la poesía. Pero poetizar y pensar no son, a su vez, lo mismo [... la filosofía y la poesía pueden hablar de la nada, porque en ellas] impera una esencial superioridad del espíritu frente a toda mera ciencia»

¿En qué consiste esta superioridad de la filosofía y de la poesía? En que: «el poeta habla siempre como si el ente se expresara y hablara por primera vez». Es decir, en que se retrotrae al aparecer primigenio, no se conforma y refugia en el lenguaje ya construido, hecho de (52) «cápsulas en las que las cosas se empaquetan para el comercio del que habla y escribe», es decir, hecho de conceptos abstractos, vacíos de contenido intuitivo y de suyo repetibles, escindidos de la realidad siempre cambiante. El auténtico pensador, en cambio, igual que el poeta, hablaría en carne viva, pegando su cuerpo y su alma a la realidad.

El problema de la lógica y de los conceptos se plantea de manera flagrante en la pregunta por el ser, pues, de hecho, la filosofía clásica afirmaba que: (77) «el concepto del ser es el más universal (...) Su dominio de validez se extiende a todo y a cada cosa en particular, inclusive a la nada, que en cuanto es pensada y dicha, también "es" algo".

Heidegger rechaza este planteamiento clásico, pero no dice por qué, simplemente establece una disyuntiva: o bien este planteamiento es el correcto, o bien «el ser tiene una esencia por completo diversa, y con ello es cualquier cosa menos el objeto de una "ontología”, supuesto que se tome esta palabra en la significación habitual». Esa significación habitual sería la establecida en el siglo XVII: (78) «El título “Ontología” se acuñó en el siglo XVII. Designa la elaboración de la doctrina tradicional del ente»; entendida como: «el análisis y la ordenación escolar de lo que para Platón y Aristóteles, y después para Kant, fue una pregunta». Es decir, la rutina y el formalismo conceptivo de la "escuela» habrían desactivado el preguntar mismo. La reflexión se habría perdido, no sería ya un verdadero pensar, que es vivir en carne y hueso, auténticamente, individualmente, en la pregunta, sino un mero juego de conceptos vacíos. Todo concepto, por el hecho de ser concepto, se petrificaría; nace, sí, en una experiencia originaria, pero inexorablemente se petrifica y se escinde de ella. Si no se vive de la experiencia originaria se corre el riesgo de vivir en un submundo de puro lenguaje muerto. Si fuere esto lo que Heidegger quiere decir, no es para tanto, porque los conceptos pueden mantenerse vivos. ¿Es acaso imposible que se mantengan vivos en una escuela? No es imposible, y, en todo caso, cuando ocurre, pues ya está, otras vidas podrán revivificarlos o crear otros nuevos. Pero, en todo caso, la vida auténtica puede acontecer en una escuela, si es que en ella se busca sinceramente la verdad y se comparte la búsqueda; la autenticidad no tiene por qué ser eremita. En la posición de Heidegger no se trata tanto de 
una especie de inexorable inadecuación de los conceptos por ser construcciones subjetivas e históricas de la inteligencia, sino de una especie de inevitable degradación de la vida, de una inexorable caída en la existencia impropia o inauténtica, que se manifiesta de forma esencial en el lenguaje. Pero esta es, precisamente, la cuestión que interesa dilucidar: si la inteligencia concipiente es por esencia caída o no. Nietzsche jugó con esta ambigüedad. Su radical oposición al socratismo retomando la tradición del escepticismo sofístico, se expresó como una forma radical de irracionalismo, que renegaba de la inteligencia como enfermedad de la voluntad de poder descendente. En el fondo todo es fuerza, interés de poderío, construcción, y por lo tanto, metáfora. La verdad no sería más que una urdimbre inventada en servicio a la voluntad de poder. Pero, la cuestión decisiva es si la experiencia originaria, que según Heidegger acontece y se expresa fundamentalmente en el pensar y en el poetizar, no se recubre legítimamente - y, quizá, hasta necesariamente- con conceptos. «Legítimamente» quiere decir que éstos no deforman ni falsifican, sino que iluminan, la experiencia originaria. Esta es precisamente la cuestión que interesa dilucidar en Zubiri. ¿Es la abstracción una disecación de la experiencia? ¿Qué efectos produce en orden a la verdad la mediación conceptual del logos?

Pareciera que Heidegger sostiene que la pérdida de sentido del ser no es más que un caso particular de la general pérdida de sentido de las palabras en la historia:

(88) «muchas palabras y, justamente las esenciales, se hallan en el mismo caso [que el ser], o sea, que en general el lenguaje está gastado y mal empleado. Constituyen un medio de intelección inevitable, pero mostrenco, arbitrariamente aplicable, tan indiferente como los vehículos de transporte público, como los tranvías, a los que cualquiera asciende o de los que cualquiera desciende. Cada uno habla y escribe sin impedimentos y ante todo, sin riesgo, usando la lengua al azar. Sólo los menos son todavía capaces de descubrir, en toda su importancia, la torcida relación, o falta de ella, entre la existencia actual y el lenguaje»

«Indiferencia», lenguaje para «cualquiera» y «sin riesgo, delegación de la vida personal en los flujos impersonales de las masas; he aquí las notas de la caída. El concepto, que se fija en la palabra y en un uso institucional, se convierte en algo público y abandona el terreno de la vida, que es individual, concreta, comprometida, intuitiva e irrepetible ¿Irrepetible? Esta es la cuestión. El contenido abstracto de los conceptos refiere a universalidades repetibles e intersubjetivamente compartibles. Wittgenstein, a la vez que niega las significaciones universales, insiste en que siempre se vive en la exterioridad del lenguaje, en el lenguaje público (teoría del significado como uso e institución e imposibilidad de los lenguajes privados), situación que sería insuperable. Heidegger, en cambio, cree que «unos pocos» podrían esquivar la caída en la exterioridad del 
lenguaje, en la impropiedad del «man», pues: (89) «la esencia y el ser hablan en el lenguaje», en el lenguaje personal propio, se entiende 4 .

Sin embargo, la pérdida de la pregunta por el sentido del ser, el vaciamiento del sentido originario de esta palabra, la paulatina y completa desaparición de su fuerza nominal, no es, como a veces parece sugerir, un caso más del vaciamiento del lenguaje, de su desgaste. Al contrario, Heidegger sostiene que el origen de este vaciamiento del lenguaje está en el olvido del ser: «la razón propiamente dicha de toda nuestra errada relación con el lenguaje está en la destruida referencia al ser como tal (...) en todos los casos su destino se funda en la referencia de un pueblo al ser; para nosotros la pregunta por el ser se entrelaza íntimamente con la interrogación por el lenguaje».

Si el decurso histórico produjo el vaciamiento del sentido originario del ser para los griegos, ahora Heidegger se propone deconstruir este lenguaje desgastado para descubrir en él las trazas históricas de su originario esplendor. En el capítulo II ("Sobre la gramática y etimología de la palabra "ser”») Heidegger lleva a cabo esta tarea: (96) «Se considera que el lenguaje rige (...) en algo que también es, que es un ente entre otros. Por eso, en su concepción y determinación tiene que poderse captar el modo según el cual los griegos entendieron el ente en su ser».

Parte del hecho de que «el ser» es una sustantivación del verbo «ser». En cambio, hay otros sustantivos que no parecen provenir de verbos. La mentalidad occidental se acuñó al fijarse la gramática griega. Esta fijación del lenguaje, en particular la estructuración en nombres (övo $\mu \alpha)$ y verbos ( $\dot{\eta} \eta \mu \alpha)$ está «en el más inmediato e íntimo vínculo con una concepción e interpretación del ser» (94).

Heidegger rastrea las trazas históricas del lenguaje en Platón, autor fundamental donde puede verse este proceso de consolidación del lenguaje griego. En Platón las palabras aparecen divididas en un doble género: los nombres, que manifiestan cosas, y los verbos, que manifiestan un hacer. Las cosas y el

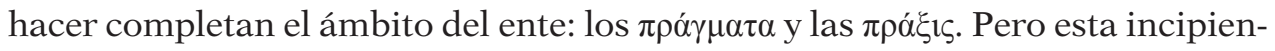
te estructura del lenguaje con el correlativo sentido del ser para los griegos se habría fijado con Aristóteles:

${ }_{4}$ O sea que Heidegger en lo que a este aspecto se refiere, a pesar de todo, se inscribe en la tradición socrática - después agustiniana- que sitúa el lugar ontológico de la verdad en la vida interior de personas individuales. Cf. GARCíA-BARÓ, M. (2005), Filosofía socrática. Salamanca, Sígueme. El autor desentraña el personalismo socrático basado en la primordialidad moral del Uno (del alma, del Yo, que comunica con Dios) frente a la opinión de los Muchos, que rehúye el absoluto refugiándose en el orden establecido en el tiempo en torno a las honras públicas, la fama y la riqueza. La norma moral de esta opción que rehúye la intimidad auténtica de la persona es: (p. 51) «No hagas nunca nada que pueda poner en peligro tu prestigio ante los Muchos (...) lo que les parece ser, cuando les parece bien». Frente a ella, la certeza de Sócrates: (p. 52) «la primera verdad (...) según el Uno (...) es: No obres mal, sin consideración alguna a las consecuencias». 
(97-98) «Los nombres $\pi \tau \tilde{\omega} \sigma ı \varsigma$ у है $\gamma \kappa \lambda ı \sigma ı \varsigma$ significan caer, perder el equilibrio e inclinarse. En esto reside un des-viarse de lo que está erguido y recto. Pero a este estar-allí en sí erguido, al llegar a ser estante y permanecer como estante, los griegos lo entendieron como ser. Lo que de este modo se hace estante y llega a ser en sí constante se instala libremente y desde sí mismo en la nece-

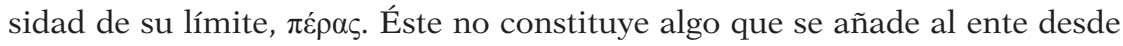
fuera. Menos aún es un defecto, en el sentido de una limitación perjudicial. El sostenerse y refrenarse dentro de límites; el tener-se a sí mismo, en lo cual se sostiene lo constante, es el ser del ente, es lo que hace que el ente sea tal, a diferencia de lo que no es. De acuerdo con esto, hacerse estante significa

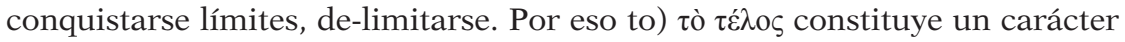
fundamental del ente, lo que no significa fin ni meta, sino término (...que) es la terminación en el sentido de plenitud (...) Lo-que-en-sí-se-sostiene-allí (das in-sich-da-stehende), visto desde la contemplación, llega a ser lo-que-se-ponealli (Sich-dar-stellende), lo que se presenta o expone con el aspecto que manifiesta. Al aspecto de una cosa los griegos lo llamaban عĩos o idea. Al comienzo

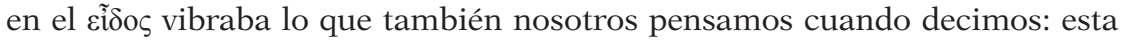
cosa tiene un rostro, ella puede hacerse ver, está presente. La cosa "está quieta”, descansa en el aparecer, es decir, en la mostración de su esencia. Todas las determinaciones del ser hasta aquí detalladas, se fundamentan y reúnen en lo que los griegos experimentaron incuestionablemente: en el sentido del ser y que llamaron ov̉øí $\alpha$ o, de un modo más completo, $\pi \alpha \rho o v \sigma i ́ \alpha$. La habitual falta de reflexión traduce esta palabra por "sustancia" y con ello pierde todo sentido [en alemán se traduce mejor] An-wesen: estar-ante. Designamos de este modo al cortijo o propiedad en sí cerrada [y lo mismo significaba también en griego] Algo está-ante. Se sostiene en sí y se presenta así. Es. Para los griegos, "ser" significa, en realidad, el estado de presencia (Anwesenheit) [De aquí surgió el concepto griego de naturaleza, a partir de] pv́øıs, que significa un "erguirse que brota", un desplegarse que permanece en sí. En esta fuerza imperante se incluyen y manifiestan el reposo y el movimiento a partir de su unidad originaria. Dicha fuerza originaria es la subyugante pre-esencia... en la cual lo presente esencializa como ente. Esta fuerza imperante, sin embargo, sólo surge de lo oculto, o dicho en griego: acontece la $\dot{\alpha} \lambda \eta \dot{\theta \varepsilon} 1 \alpha$, en cuanto aquella se impone como un mundo. Sólo a través del mundo el ente llega a ser algo que es».

La acentuación de la "presencia» (del «Sich-dar-stellende») produjo una primera debilitación del sentido originario del ser (del «in-sich-da-stehende»). Así, «el ente se convierte en objeto, sea de la contemplación (aspecto, imagen), sea del hacer, entendido como producto y cosa de cálculo. Lo que mundaniza en sentido originario púøıৎ se reduce ahora a ser modelo de imitación y copia». Entonces, el sentido originario del ser para los griegos sería el de constancia; que encerraría a su vez dos sentidos: a) estar-en-sí-erguido-en-cuanto-es-lo-queestá-surgiendo; b) perdurar-constante-permanente. Frente a ello el no-ser es el salir de la constancia surgente: ex-sistir. Esta misma dualidad ser/nada se 
reproduce en el lenguaje con la dualidad nombre ( $\dot{\rho} \tilde{\eta} \mu \alpha)$ y sus declinaciones o modulaciones derivadas: $\ddot{\varepsilon} \gamma \kappa \lambda \iota \sigma \varsigma^{5}$.

Históricamente el verbo ser, a través del infinitivo como forma intermedia, ha derivado en el sustantivo «ser», el ser, como si fuera realmente un nombre. Esto le sirve a Heidegger para explicar la inconsistencia de la palabra ser:

(105-106) «"El ser" se convierte ahora, él mismo, en "algo que es"; sin embargo sólo se trata como es manifiesto de un ente y no del ser. Si el ser mismo fuese algo que es en el ente, tendríamos que encontrarlo, máxime cuando el ser ente se nos ofrece en el ente (...) ¿Todavía nos extrañaremos de que el ser sea una palabra hueca, si ya la forma verbal se aplica a una evacuación y a la aparente fijación del vacío? La expresión "el ser" constituye para nosotros una advertencia. No nos dejemos desviar por la forma en el extremo vacua de un sustantivo verbal»

Y en este punto el pensador alemán plantea toda una retahíla de preguntas:

(109) «1) ¿Qué clase de abstracción estaba en juego en la formación de la palabra "ser"? 2) ¿En general, se debe hablar aquí de abstracción? 3) ¿Cuál es en general la significación abstracta que resta? 4) ¿El suceso que en este caso se manifiesta.... se puede explicar diciendo meramente que algo se ha perdido en él? 5) ¿Qué dirección significativa se conserva a través de la compleja confusión de tal mezcla'? (...) ¿El sentido del ser que sobre la base de la mera interpretación lógica y gramatical se presenta como "abstracto" y, por tanto, derivado, ¿puede ser en sí pleno y originario?»

La respuesta a esta última pregunta, que en cierto modo sintetiza todas las anteriores, es que no: «el verbo "ser" es vacío y de flotante significación». Pero, en todo caso, quizá lo decisivo (al margen del problema de la primacía de la presencia) es que esta tergiversación, esta pérdida del suelo originario del auténtico sentido del ser para los griegos no es más que un caso particular de las desviaciones que el lenguaje puede producir al pensar. Esta es, pues, quizá, en el fondo la cuestión decisiva, el leguaje como posibilidad de ocultamiento. Y aquí es donde entra la cuestión del concepto como útil peligroso, tesis común a filósofos como Nietzsche, Kierkegaard - entre nosotros Unamuno-y también Wittgenstein. El concepto es un sucedáneo, una pérdida, el rendimiento de una mera estratagema como operación lingüística, algo derivado y epidérmico respecto de la experiencia originaria pre-racional, que es donde se da la plenitud. Por consiguiente, la consigna, en el caso particular de la pregunta por el ser, será: (114) «iApartémonos de esa hueca y universal palabra y atengámonos a las particularizaciones de los dominios singulares del ente mismo»

Pero yo me pregunto: ¿no está el concepto originariamente vinculado al عĩos con el que la cosa física, la sustancia (en el sentido que describía el propio

5 La tesis hermenéutica de la imposibilidad de un lenguaje inmediato que nombre lo que en sí mismo es, la imposibilidad de un lenguaje (conceptos) propio se expresa magníficamente en la tesis de Paul Ricoeur en torno a la metáfora. Todo sería Ě $\gamma \kappa \lambda \imath \sigma ı$. Por ejemplo, Paul Ricoeur (2001), La metáfora viva. Madrid: Ed. Cristiandad/Trotta, $2^{a}$ ed., pp. 26-27. 
Heidegger más arriba) se hace originariamente presente a la inteligencia?; ¿y no es este mismo concepto el que, efectivamente, "guarda» ese cĩo $\delta$ de origen físico como un universal sedimentado y asentado en la intersubjetividad para proponer la repetición de aquella experiencia originaria en que se engendró para hacer posible la memoria y la comunicación?; ¿y no es condición de la posibilidad de dicho depósito de significación y de la repetición (repetición de experiencia originaria y repetición del mismo cĩós en sustancias distintas) el que haya en la realidad elementos «universales», repetibles, que determinan simultáneamente a múltiples individuos, denotados por el concepto? Si no hubiese factores repetibles comunes en la experiencia individual ¿cómo podría ser «dicha» —nombrada- la realidad?; y ¿cómo podríamos, si no, comunicarnos? ¿Es que acaso Heidegger no presenta lo que considera originario y verdadero con conceptos, con lenguaje? Estas mismas preguntas revertirán sobre Zubiri para tratar de ver cómo reacciona ante ellas su pensar.

Heidegger se corrige, no obstante, a sí mismo y señala que por muy gastada que esté una palabra (como la palabra «ser»), siempre nombra algo:

(117) «No existe ninguna palabra vacía: aunque gastada por el uso siempre sigue teniendo contenido. El nombre "ser" conserva su fuerza de nombrar. Aquel precepto “¡apartémonos de esta palabra vacía 'ser' y dirijámonos a los entes particulares!” no sólo constituye una indicación precipitada, sino en extremo dudosa»

Aquí se ve el carácter problemático de todo el planteamiento de Heidegger. No creo que se trate en el caso del ser de una degradación del lenguaje o de un desgaste de la palabra, o, al menos, el problema no es sólo lingüístico, sino real. Es difícil saber a qué se refiere el ser, porque, efectivamente, alude a lo más trascendental, a aquello que afecta a cualquier contenido de la conciencia ponente, la dificultad es real, no se trata de que el «ser» tuviera un sentido concreto en la Grecia clásica y lo hayamos olvidado. Podría haber ocurrido, eso sí, que los griegos hubiesen pensado muy bien el problema, con mucha lucidez, y que posteriormente, como resultado de una vida inauténtica, que no se plantea los problemas radicales, se hubiese olvidado la pregunta por el ser... Eso, que yo creo que no es verdad, sería otra cosa. En este caso, y Heidegger juega con esa ambigüedad, podría tratarse de que la indominabilidad del acontecer histórico humano impidiese que las experiencias históricas originarias pudiesen repetirse a capricho, el desvelamiento, entonces, de ámbitos enteros de realidad, no estaría a nuestro libre albedrío: yo ya no puedo revivir los sentidos vividos en mi niñez... Si fuese así, sí podría decirse que hubo una etapa verdaderamente filosófica en la historia de la humanidad (en nuestro caso, la de los griegos), y que ella pasó para siempre: ¡Es el problema (derridiano) de la repetibilidad de experiencias originarias! iqué es lo que buscan los conceptos! Se trata, entonces, de si hay elementos repetidos en la realidad y, en todo caso; repetibles, en última instancia, se trata del eterno problema de si hay elementos estables en la realidad o, por el contrario, todo devine continuamente sin ningún momento de permanencia. Permanecer es repetirse. En el sentido originario del ser para 
los griegos - que Heidegger pretende haber descubierto por deconstrucciónestá contenido este sentido de estabilidad y permanencia, y, por lo tanto, de repetición: "permanecer como estante en su límite»; «la mismidad», «lo constante», «la quietud de la cosas», en definitiva, la ov́cía. Hay, pues, un sentido originario y legítimo de sustancia que Heidegger no rechaza y que, por otra parte, es recogido por Aristóteles: la sustancia como el sustrato ontológico de permanencia.

Heidegger, empero, parece dar por sentada la incapacidad de los conceptos para retener la experiencia originaria y hace una propuesta muy parecida a la del segundo Wittgenstein:

(117-118) «En el lugar del concepto universal "ser"' pongamos a modo de ejemplo la representación general árbol. Ahora bien, si debemos decir y delimitar qué es la esencia del árbol, nos apartaremos de la representación general y nos volveremos a las especies particulares de árboles y a los ejemplares singulares de estas especies [... ahora bien] ¿Cómo hallaríamos en general el tan invocado hecho particular, los árboles singulares como tales, es decir, como árboles? ¿Cómo, en general, podríamos buscarlos en tanto son árboles, si de antemano no nos fuese patente la representación de lo que es un árbol en general? Si esta representación general "árbol" fuese tan indeterminada y confusa [no podríamos encontrar árboles...]. Si es cierto que para una más rigurosa determinación de la diversidad esencial de la esencia "árbol" tenemos que realizar una pasada a través de lo particular, seguirá siendo al menos tan cierto como eso, que la aclaración de aquella especificidad esencial y de la esencia sólo se produce y acrecienta cuanto más originariamente nos representemos y conozcamos la esencia general árbol, y desde aquí, la del "vegetal", la de lo "viviente" y de la "vida". Podríamos registrar miles y miles de árboles: si no nos alumbrara un saber desplegado de la arboreidad y no se determinara con evidencia desde sí mismo y desde su fundamento esencial, todo sería frívola empresa, pues frente a los meros árboles no veríamos el árbol»

Se trata del círculo hermenéutico, que ya pusiera Platón de relieve en el Menón o Dilthey en la Esencia de la Filosofía ${ }^{6}$, por ejemplo: para alcanzar a conocer la esencia de la filosofía necesitaría conocer obras filosóficas concretas para conocer en ellas su peculiaridad en tanto que filosóficas; pero, justamente para poder seleccionar estas obras discerniéndolas de otras no filosóficas, ya tendrían que saber lo que trato justamente de buscar, a saber, cuales son filosóficas y cuales no. Heidegger aplica el mismo razonamiento al concepto de ser, y lo que afirma es que algo debemos entender por él, debemos tener una precomprensión del ser. Se dan, pues los dos hechos a la vez: la indeterminación del sentido del ser y una previa comprensión suya: (119-124) «La necesidad de que ya entendamos la palabra "ser" es suprema e incomparable (...) entendemos al ser, puesto que lo diferenciamos con seguridad del no-ser (...) los entes

6 Platón, Menon 80 d 6. W. Dilthey (1963), La esencia de la filosofía, Obras Completas. México: FCE vol VIII, pp. 147 y ss. 
particulares sólo se nos pueden manifestar abiertamente como tales si ya comprendemos de antemano y en cada caso, el ser en su esencialización».

Heidegger parece partir de la teoría agustiniana del «verbo interior» al diferenciar entre: 1) «significante», 2) «significado» («lo que uno se representa en general») y 3) «referente» (124). Pero esta estructura no sirve para dilucidar el sentido de la palabra «ser», ya que el ser «no es cosa alguna, si por cosa entendemos un ente cualquiera» (125). ¿Cuál es, pues, su sentido?:

(128-143) «en el "es" se nos manifiesta el ser de un modo complejo (...) Sólo porque el ser sigue siendo en sí indeterminado y vacío de significación puede prestarse a usos tan heterogéneos y llenarse y determinarse "en cada caso según las circunstancias" (...) Sin embargo, la diversidad de las significaciones no es arbitraria (...) un rasgo único y determinado atraviesa todas esas significaciones (...) la limitación del sentido del "ser" se mantiene dentro del ámbito de la presencia y de lo que tiene el carácter del estar-ante de la consistencia y de la subsistencia, de la morada y del advenir»

Salvando las distancias, se trata del correlato noemático de los actos ponentes en Husserl, o de la formalidad de realidad en Zubiri: un de-suyo, que hace frente. Esto concuerda, según Heidegger, con la concepción de los griegos, a quienes: «el ser se les manifestó como pv́øıc. La fuerza imperante (walten) que brota y permanece es al mismo tiempo y en sí misma la apariencia que aparece (...) hallarse en sí no significaba para los griegos sino hallarse-allí [da-sein], el hallarse-a-la-luz». Por eso Heidegger piensa que la atribución a los griegos de un realismo ingenuo no es más que una huera construcción:

«[al referirnos a los griegos] tenemos que prescindir de títulos tales como "subjetivo" y "objetivo", "realista” e "idealista” (... para ellos) el ser esencializa como pv́бis. La fuerza imperante que brota es aparecer; ella lleva al presentar. En esta circunstancia está implícito el hecho de que el ser, el aparecer, hace de desocultamiento, $\dot{\alpha} \lambda \hat{\eta} \theta \varepsilon 1 \alpha$ (...) la verdad pertenece a la esencialización del ser. Ser ente implica: presentarse, aparecer manifestándose, ofrecerse, exponer algo. No ser, por el contrario, significa, apartarse de la aparición, de la presencia»

La decadencia, la pérdida de este originario sentido del ser se habría producido con el humanismo griego, que separa el aparecer físico del aparecer a la inteligencia: «sólo en la sofística y en Platón la apariencia fue explicada como mera apariencia y con ello disminuida». El sentido genuino de apariencia no se refiere a la apariencia a un sujeto cognoscente, sino a la apariencia como el aparecer en la realidad, como surgir que acontece, como esencialización del ser en los entes. Aunque lo decisivo es que este aparecer va esencialmente vinculado al aparecer a las inteligencias. El descoyuntamiento de ambos apareceres, y, sobre todo el debilitamiento de la primacía del aparecer físico produjo un desplazamiento del ser en cuanto mera ióśa a un lugar suprasensible ¡He aquí el idealismo, que también Zubiri recriminará a la tradición metafísica occidental! Sobre esta base Heidegger hace una interpretación de Platón similar a la de 
Nietzsche, vinculándolo al cristianismo como decadencia y tergiversación de lo genuinamente griego al escindir la realidad en dos mundos:

(143) «Se abrió el abismo, ópıøuós, entre el ente que sólo es susceptible de aparecer aquí abajo y el ser real que se halla en algún lugar de allá arriba; es decir, se abrió aquel abismo que más tarde estableció la doctrina cristiana, la cual transformó lo inferior en lo creado y lo superior en el Creador, pudiendo, con las armas así transformadas, oponerse a la antigüedad (entendida como paganismo) y disimularla. Por eso Nietzsche dijo con razón que el cristianismo es un platonismo para el pueblo»

He aquí la hipóstasis de los conceptos como contenidos universales: la hipóstasis de las ideas.

Por consiguiente, la posición genuinamente griega, previa a la hipóstasis platónica, sería la de afirmar que el ser consistiría en un brotar que esencializa a la vez se hace presente a las inteligencias. No hay separación entre ambos apareceres: el físico y el aparecer a la inteligencia. Esto es lo que Zubiri quiere recuperar con su concepto de actualidad en la aprehensión primordial de realidad, en la que no hay dualidad óntica entre la cosa física que aparece y el aparecer mismo. La filosofía humanista griega habría roto esta unidad entre el aparecer físico y el aparecer a la inteligencia. También Heidegger pretende retrotraerse al sentido originario del ser, previo a su dislocación, en el que ser y aparecer (cualquier aparecer, incluido el «parecer»: la apariencia ocultadora) van de la mano.

(142) «puesto que el aparecer le pertenece al ente mismo, también le corresponde la apariencia».

Y en (146):

«el parecer es como una variedad del ser, tal como las caídas (...) al ser mismo en cuanto aparecer le corresponde la apariencia (Schein) (...) La apariencia acontece en el ente mismo y con él. Pero la apariencia no sólo hace aparecer al ente como tal como lo que en sentido propio no es; no sólo disimula al ente del cual es apariencia, sino que se encubre a sí misma en tanto apariencia, puesto que se muestra como ser (...) como encubrimiento y fingimiento decimos que la apariencia engaña (...) entiendo como error el espacio que se abre dentro del entrelazamiento del ser, el desocultamiento y la apariencia (...) pertenecen necesariamente al ser tanto la verdad, en el sentido del desocultamiento, como la apariencia, en tanto determinada manera del mostrarse naciente»

Tan originaria como la verdad sería, pues, la apariencia —el engaño, la ilusión, el error-, de manera que el mayor valor dado a la verdad tan sólo se explicaría por la pretensión de los inicios del pensar de «refrenar la penuria del ser en la apariencia». La valoración moral de la verdad - y la correlativa desvaloración de la apariencia - no tendría otro fundamento que ese. La cuaterna sería: ser-desocultamiento-apariencia-no-ser. Justamente, en esta cuádruple dimensión del ser se fundarían las tres vías que Parménides postula para el hombre: 1) El camino de la verdad (que es el camino hacia el ser en el 
desocultamiento — ser y desocultameinto irían juntos-) y que Heidegger considera ineludible. 2) El camino hacia el no-ser (que es intransitable, pero que según Heidegger tiene que ser conocido como tal). Estas dos vías se suponen mutuamente, del mismo modo que el ser y el no-ser se presuponen: «tienen que ser pensados en unidad (pues...) la circunstancia de que la nada no sea algo que es, no excluye en modo alguno el hecho de que a su manera pertenezca al ser» (149). Por último, 3) el camino de la apariencia, que es siempre accesible y transitado, pero eludible según Heidegger, y que sería el referido en el fragmento $6^{\circ}$ de Parménides, donde el pensador griego:

(149) «muestra un tercer camino, opuesto al segundo, que es inaccesible y por tanto estéril, ya que se dirige a la nada (...) el de la $\delta$ óg $\alpha$ en el sentido de la apariencia, sobre este camino el ente se ve ora de un modo ora de otro. Aquí sólo dominan en todos los casos las opiniones. Los hombres pasan de un dictamen a otro en un constante vaivén. Mezclan entre sí al ser con la apariencia (...) este camino es constantemente frecuentado, de tal modo que el hombre se pierde íntegramente en él. Tanto más necesario es conocerlo como tal, puesto que en la apariencia, y contra ella, el ser pierde sus capas encubridoras».

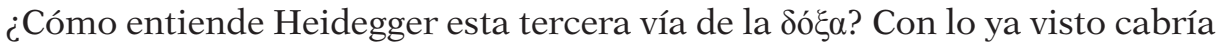
pensar que se trata de los hombres que viven instalados en la vacuidad del lenguaje, es decir, de los conceptos, habiendo perdido la autenticidad de la vida intuitiva individual concreta. Incluso la vida científica formaría parte de esta senda de caída. Pero esta vía de la opinión, común a los «muchos», aunque siempre se vuelva a caer en ella, puede no obstante según Heidegger ser abandonada, existiendo la posibilidad de transitar el camino de la sabiduría, aunque éste no es sólo el camino de la verdad, sino en cierto modo la conciencia socrática de la verdadera situación humana en relación a ella:

(151) «Por eso el hombre verdaderamente sabio no es aquel que persigue a ciegas una verdad, sino sólo aquel que conoce constantemente esos tres caminos: el del ser, el del no-ser y el de la apariencia. El saber meditado -y todo saber es meditación - sólo le es dado al que haya experimentado el alado impulso del camino hacia el ser, al que no le haya sido extraño el espanto del segundo camino hacia el abismo de la nada, y al que haya aceptado, como constante necesidad, el tercero, el de la apariencia. A ese saber pertenece lo que los griegos en su gran época llamaron $\tau o ́ \lambda \mu \alpha$ : atreverse simultáneamente con el ser, el no-ser y la apariencia»

Heidegger está hablando de la sabiduría, no como una vida basada en la verdad a secas, sino como una vida basada en la verdad del hombre, según la cual a éste no le queda otra que vagar en una especie de errancia entre los tres caminos. No obstante, esta verdad antropológica es también ontológica (si se quiere, metafísica), porque el ser y su verdad (gracias al Dasein) son inseparables, del mismo modo que el ser y sus espejismos, sus apariencias. En todo caso, la sabiduría estricta propia del hombre consiste en esto, en el conocimiento de su inexorable errancia entre las tres vías; y entonces, en esta solidez 
existencial, en este atenerse a la realidad y hacerse cargo de ella, no entran sólo aspectos generalísimos, trascendentales, ontológicos, sino que entran también aspectos ónticos, de contenido, por ejemplo, hacerse cargo de la finitud ique no es la nada! así como aprehender las «esencias» ónticas en las que el ser se esencializa. Los conceptos no quedan al margen, simplemente se orientan a parcelas más o menos trascendentales. El aplomo de una persona viene dado por su instalación sólida (de peso y firme: aplomada) en la irrefragable realidad. La solidez de la ciencia viene dada cuando ella busca realmente la verdad, aunque los resultados de su búsqueda fueren provisionales, pero el verdadero científico tiene que estar comprometido con la solidez y la fuerza de la realidad, no puede ser como alguien que juega.

Por otra parte, ¿es verdad que la no-verdad, la apariencia como engaño y disimulo, pertenece esencialmente al ser? Heidegger es muy ambiguo a este respecto. A veces sugiere que es así, y otras parece estar simplemente refiriéndose a la finitud de las perspectivas humanas del ser (siempre cambiantes), que sería el terreno propio de la opinión. En todo caso no creo que la apariencia engañadora pertenezca originariamente al ser. Tal tesis volvería a romper, evidentemente, con la genuina tradición metafísica, que sitúa en la médula de su propuesta la verdad ontológica (en el sentido de que el ser no puede fundar un falso aparecer). Para el cristianismo el disimulo, la falsa apariencia, no es propia del ser, sino del mal introducido en el mundo por el pecado. Pero también es así para la escuela socrática. El ser, dice Platón, ya desde joven ${ }^{7}$, no puede ser causa de un falso aparecer. Ciertamente la reina celosa se disfraza de anciana bondadosa para engañar a Blancanieves; el mismo Satanás, se disfraza de serpiente del Paraíso para engañar a Eva; pero esta falsa apariencia es verdadera apariencia de "anciana bondadosa» y de «serpiente del Paraíso». Por fuera es una verdadera anciana y una verdadera serpiente. Es por dentro, en lo oculto, en la esencia real, donde no se trata de una anciana bondadosa ni de una serpiente del Paraíso. El falso aparecer se produce por el mal, que introduce un desorden en la coherencia de los fenómenos: el exterior que aparece no coincide con el interior que no aparece, de manera que incita a alguien a un juicio erróneo. La piel rugosa de la viejecita es verdadera piel rugosa, y la figura y el color de manzana también, pero ambas realidades superficiales no concuerdan con la realidad profunda y oculta, que no corresponde a la que debería ser la esencia de la cosa (no es una verdadera anciana, ni una verdadera manzana). Hay una manipulación de la realidad por parte del mal, que introduce un desorden en ella y fuerza el error en las personas que aún confían en el orden.

La apariencia va vinculada al devenir y el devenir a la apariencia en tanto en cuanto lo que deviene, ora es de un modo (aparece como una cosa), ora es

7 Platón, Hipias mayor, 294 e 3: «una misma causa no podría hacer que las cosas parezcan y sean bellas o de otra cualidad». El ser, efectivamente, es causa necesaria del aparecer, pero no es causa suficiente, pues cosas diferentes requieren de causas diferentes. En ese caso, todo falso aparecer se fundará en quien «recibe» el aparecer, pero no en el ser. 
de otro (aparece como otra). En el fondo de la concepción heideggeriana del ser late una concepción análoga en cierto respecto a la de Hegel. Está el ser en sí originario, que permanece oculto (Hegel diría, sin autoconciencia), pero se despliega, se "esencializa» (Hegel diría: sale de sí, se niega), desvelándose en su verdad: (152) «En su origen, el ser permanece replegado, sea por gruesos velos y caparazones, sea por el más superficial disimulo y encubrimiento». Hay dos planos: un primer plano de Ser/devenir/apariencia; y un segundo plano: el del pensar. Este segundo plano (el pensar) se opone al primer plano (el ser y sus modulaciones - devenir y aparecer-). El pensar decide sobre el ser interpretándolo. El pensar entiende y concibe el ser. En esta estructura hay que situar cualquier actividad cognoscitiva humana, ya sea científica, hermenéutica o metafísica; aunque Heidegger parece hacer prevalecer la segunda:

(155) «todo entender, en cuanto modo fundamental de la patentización, se debe mover en una órbita visual determinada [desde un topos, desde un contexto] El reloj, por ejemplo, permanece para nosotros cerrado en lo que es, hasta que no conozcamos de antemano algo así como el tiempo, el cálculo del mismo, su medición. La órbita visual de su aspecto ya tiene que estar de antemano abierta. La llamamos "órbita previa de visión", "perspectiva"».

La cosa es que el ejemplo que pone Heidegger es el de un útil: el reloj, pero la tesis hermenéutica la aplica al ser en general. ¿Qué es, entonces, pensar? Pensar es: 1) idear/planear/tender-hacia; 2) recordar/imaginar/representar/opinar; y 3) discurrir/reflexionar/aquello-que-hace-el-pensador. Y estos tres sentidos de pensar se resumen en los tres siguientes (156): 1) El representar «a partir de nosotros» entendido como peculiar y libre conducta; 2) El representar entendido como vehículo analítico; y 3) La captación representativa de lo universal.

Todo pensar es, pues, re-presentar. Según cómo se realice cada una de estas formas del pensar tendremos un pensar «superficial o profundo, vacío o pleno de contenido, facultativo u obligatorio, juguetón o serio» (156)

El concepto pertenece, desde luego, a este ámbito de la representación. Pero, por muy crítico que Heidegger vaya a ser con la representación, y por tanto con el concepto, al final su «pensar», que pretende ser auténtico, también es conceptual y busca conceptos: (157) «todavía», le leemos escribir, «no hemos logrado ningún concepto suficiente del pensar (...) ¿de dónde podíamos tomarlo?»

Y comienza a hablar de nuevo de la Lógica.

(157) «[la Lógica] es la ciencia del pensar, la doctrina de las reglas del pensamiento y de las formas de lo pensado [...en ella] no desempeñan ningún papel los "puntos de vista" y las direcciones propias de las concepciones del mundo. Luego rige como ciencia segura y digna de confianza. Desde antiguo enseña lo mismo [...] La lógica es la ciencia del $\lambda$ ó este caso enunciación... ¿Por qué el pensar se determina a partir de la enunciación?»

El paralelismo con Zubiri es evidente. La logificación de la inteligencia situó a la filosofía occidental en una inversión de órdenes perturbadora: la llevó a proyectar sobre la realidad la estructura del logos predicativo humano. Y éste 
ha sido su error y su limitación. En Sobre la esencia esta tesis vertebra toda la crítica a la metafísica anterior. Todas las teorías de la esencia habrían sido viciadas por este error «logocéntrico». La teoría husserliana de la esencia como sentido, a pesar de su novedad, reposa sobre la tradicional distinción esencia/ existencia. Lo que haría la reducción fenomenológica es "reducir" la existencia para quedarnos con la pura esencia, con la verdad esencial o absoluta. Las diversas corrientes que han definido la esencia como concepto, ya sea como concepto formal en el caso de Hegel, o como concepto objetivo en el caso de la escolástica o del racionalismo moderno, no habrían hecho sino reproducir el mismo error, porque el concepto es el rendimiento del logos predicativo, es decir, de un modo ulterior de la inteligencia, que, antes que en lógica, consiste en aprehensión primordial de realidad. Y otro tanto acaece en la concepción aristotélica de la esencia como correlato real de la definición esencial. La definición esencial está ella misma definida a partir de la estructura jerárquica de los conceptos en géneros, especies y diferencias. Pero aquí ya se habría colado de nuevo la estructura del logos predicativo y la preeminencia idealista dada al concepto sobre la realidad física. Hay multitud de textos sobre ello a lo largo de toda la obra de Zubiri. En Sobre la esencia, obra más cercana al espíritu de Heidegger que la Trilogía sobre la inteligencia, los textos son igualmente múltiples. Por ejemplo, en la página 9 leemos ${ }^{8}$ :

«[si] esencia y existencia son tan sólo dos momentos o aspectos que ofre-

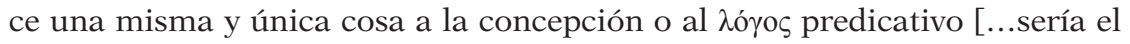
resultado] de un falso conceptismo [que] habría conducido a convertir estos dos aspectos conceptivos de la realidad en dos momentos físicamente distintos de ella».

Y, justamente, en el contexto de la crítica al logicismo moderno, en concreto a Leibniz, Zubiri plantea lo que a su vez son los límites del principio de no contradicción, siempre sobre la base de la irreductibilidad de la realidad a concepto, o en términos de la dualidad ser/pensar tal y como la plantea Heidegger, de la irreductibilidad del ser al pensar. A partir de esta no identidad entre ser y pensar, expone Zubiri los límites del logicismo, pues la cuestión de la "unidad" y "mismidad" del ente, requisitos fundamentales del principio de contradicción (SE, 68-69), encerraría una ambigüedad, a saber, puede referirse a «el ente en cuanto declarado, pero puede ser la cosa misma acerca de la cual pienso y hablo con mi logos». Y Zubiri se pregunta: «¿Son idénticos ambos "entes”? Ésta es la cuestión. (/) Si fueran idénticos, la realidad no sólo no sería contradictoria, sino que conoceríamos positivamente y con firmeza las condiciones y límites de su incontradicción (...) Pero es que esta identidad del ente como intención significada y como cosa $(\pi \rho \alpha ́ \gamma \mu \alpha)$ es sumamente problemática».

El problematismo del conocimiento humano viene, pues, de la mano de la estructura predicativa de su logos, y la pregunta que yo me hago es cual es el verdadero sentido y alcance de este problematismo, en definitiva, lo que me

\footnotetext{
8 Cito según la última edición; ZubiRI, X., Sobre la esencia, Madrid 2008
} 
pregunto es si la condición "lógica" (conceptual) de la inteligencia humana nos sitúa necesariamente en la vía de la opinión, o si, por el contrario, es posible para nosotros en el logos la ciencia rigurosa (die strenge Wissenschaft). A estas alturas de nuestra civilización, después de tanta barbarie y desengaño, esta pretensión de una ciencia rigurosa no despierta más que desconfianza, pero debe plantearse a pesar de esta coyuntura. Mucho de ello se juega en la capacidad de los conceptos y de la proposición para fundirse con la experiencia originaria, con la aprehensión primordial de realidad en la terminología de Zubiri, de manera que el logos no constituya una falsificación ni un dejar de lado lo real dado en aprehensión primordial proyectando sobre ello un velo de ideas, sino que, por el contrario, sea una actividad del espíritu que contribuya a iluminar y a explicitar lo real ya dado en aprehensión primordial.

Como estamos viendo, también Heidegger sitúa en el lenguaje, en la lógica, el posible ocultamiento de la verdad originaria. El propio Husserl había retrotraído la lógica formal a una lógica trascendental, que opera en los estratos originarios de la vida intencional, una ciencia del puro pensar, que piensa la génesis de los conceptos y de los enunciados, una filosofía, pues, de la lógica, una ciencia más radical y profunda que la lógica misma, pues estudia su génesis y sus fundamentos. Y, sin embargo, también ella misma aspira a conceptualizarse. En Zubiri se trata de la noología, que da cuenta del dinamismo originario de la inteligencia, y así, del logos y la lógica, pero que también ella misma es conceptual. El hecho mismo de que tanto Heidegger como Zubiri denuncien al conceptismo como un deslizamiento de la metafísica implica la capacidad de la inteligencia para superar dicho logocentrismo, pues, ¿desde dónde se hace la denuncia? Por consiguiente, hay una implicación mutua y una codeterminación originaria entre la filosofía de la lógica y la lógica, entre la noología y la lógica, entre el pensar y la lógica. La ulterioridad de la lógica es sólo relativa en este sentido. No obstante, Heidegger acentúa su ulterioridad:

(158) «la Lógica como tal sigue siendo problemática y no sólo algunos trozos o teorías singulares de ella. Por eso la Lógica se tiene que poner entre comillas. No porque pretendamos desconocer "lo lógico" (en el sentido de lo pensado rectamente). En servicio del pensar tratamos de lograr aquello desde

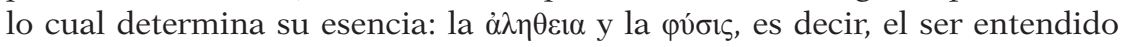
como estado de desocultamiento (...) justo lo que se ha perdido con la lógica»

Es decir, la perspectiva lógica, por ser formal, hace que se pierda la perspectiva metafísica, el ser y su modalidad co-esencial: la verdad. Este logicismo sería idealismo, porque al quedarse en el organon del conocer pierde el objeto mismo del conocimiento. Esta crítica la expresa Heidegger con resonancias retóricas nietzscheanas:

(158) « ¿desde cuando existe la lógica, que aun hoy domina nuestro pensar y decir y que desde temprano codeterminó (...) la concepción gramatical de la lengua? Desde que la filosofía griega finalizó convirtiéndose en ocupación de escuela, de organización y de técnica... en las escuelas platónicas» 
$\mathrm{Al}$ ensalzamiento de la lógica, Heidegger lo denomina «intelectualismo» (también podría haber dicho «idealismo»), y consistiría en dar preeminencia al pensar sobre el ser. Así, lo que hay que recuperar es la «esencial referencia del pensar al ser»(160).

Esta superación de la lógica — dice Heidegger- no significa situarse en posiciones irracionalistas: (160) «[no significa] la derogación del pensar y el predominio del mero sentimiento, sino que señala a un pensar que corresponda al ser de modo más originario y riguroso». Y es aquí donde Heidegger propone una serie de preguntas clave referidas a este proceso histórico de la logificación de la inteligencia: 1) ¿por qué se descoyuntó el logos de la physis?; 2) ¿por qué el logos se constituyó en la esencia del pensar?; y 3) ¿por qué el logos adquirió dominio sobre el ser?

Para desentrañar este problema reconstruye la etimología de la palabra $\lambda$ ó La cosa es que originariamente esta palabra no tendría nada que ver con lenguaje (el discurso o el decir), sino con recoger. Es exactamente lo mismo que

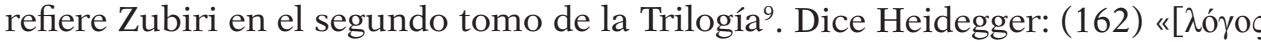
equivale a «lesen» en alemán, que es recoger, reunir] poner una cosa al lado de otra, juntarlas; pero, al mismo tiempo, destacar una cosa de la otra». Veremos la importancia de esto.

Inmediatamente pasa el filósofo alemán a pensar la oposición ser/pensar. Ser es para los griegos physis; y physis, ya lo hemos visto, es: «fuerza imperante que surge [y] en oposición al devenir se muestra como constancia [la persistencia de la sustancia], como constante presencia». Se ve aquí el punto de engarce con la idea zubiriana de realidad: modo de estar-presente. Heidegger afirma que la falsificación cristiana del pensamiento griego tiene un hito fundamental en la falsificación del pensamiento de Heráclito al presentarlo como precursor del Prólogo al Evangelio de San Juan. En Heráclito $\lambda$ ó $\gamma$ os originariamente es «lo que reúne en sentido originario», aunque, también lo utiliza en su sentido derivado de discurso o lenguaje, pero el sentido primario es el primero, que es algo físico, pues concierne al ente, al ser (y no al pensar): (168) « $\lambda$ ó ${ }^{\circ}$ s es la reunión constante, la totalidad reunida y en sí estante del ente, es decir, el ser (...)

9 ZuBIRI, X. (1982), Inteligencia y logos, Alianza Editorial\&Sociedad de Estudios y Publicaciones, Madrid, p.47: «Logos proviene del verbo légein que significa reunir, recoger. Es el sentido que sobrevive aún en vocablos tales como florilegio. En el problema que nos ocupa, los griegos anclaron su idea del légein en esta idea de reunión. Ahora bien, a mi modo de ver esto es insuficiente. Ciertamente légein significa reunir, recoger. Pero ¿reunir qué? Esto es lo que hay que empezar por decir. Los griegos no se detuvieron en este punto. Pues bien, se reúne y recoge lo que está en el campo de realidad ... légein debe servir para designar un acto de reunión campal ... De légein derivaron los griegos el vocablo y la idea de logos. Del sentido de reunir , légein pasó a significar enumerar, contar, etc. De ahí légein cobró el significado de decir... El logos tiene los [/] dos significados de «decir» (légon) y de «lo dicho» (legómenon). Los griegos afincaron su reflexión en lo dicho mismo. Cuando esto que se dice es una declaración de lo que la cosa es, entonces los griegos decían que se trata del logos por antonomasia: logos declarativo (logos apophantikós). Este logos declarativo consiste en "declarar algo acerca de algo» (légein ti katà tinós). El logos envuelve siempre una cierta dualidad de "algos"». 


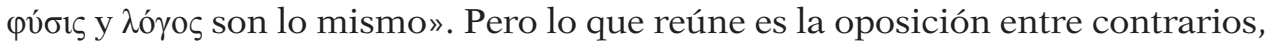
porque cada contrario exige a su contrario y así la totalidad los reúne. Esta primacía del «logos» físico lo estatuye como canon de la verdad, es decir, como canon del logos lingüístico: (170) «El decir y el oír sólo son justos cuando en sí mismos y de antemano se dirigen al ser, al Logos. Sólo donde éste se patentiza a la vez llega a ser palabra». Esta es la cuestión decisiva: si el logos humano reproduce el Logos de la realidad, entonces la verdad lógica se nutre de la verdad real. Pero esta es la tesis de la metafísica clásica. ¿Entonces? ${ }^{10}$

\section{VERDAD Y CONCEPTO EN ZUBiRI}

\subsection{El planteamiento de la cuestión en Sobre la esencia}

El comienzo de esta obra es difícil. Se empieza advirtiendo contra la progresiva desustanciación de la esencia, que tendría sus raíces en ciertos aspectos de la filosofía occidental desde sus inicios, pero que se habría agudizado en la modernidad hasta desembocar en una desustanciacion completa en el existencialismo nihilista. Inmediatamente introduce Zubiri la necesidad de recuperar la realidad física afrontando de nuevo el problema de la esencia de las cosas en sí mismo y desmarcándose del planteamiento habitual, que siempre ha partido de la dualidad esencia/existencia. La cuestión es compleja, porque Zubiri sugiere un doble origen de este erróneo planteamiento. Por un lado, sería el resultado del logocentrismo o «logificación de la inteligencia», consistente grosso modo en proyectar sobre la realidad de las cosas, consciente o inconscientemente, la estructura del logos humano. La distinción esencia/existencia sólo sería propia de las cosas qua legomena, «en tanto que expresadas en una predicación» (SE 8), pero no en sí mismas «en su estructura física (...) independientemente de toda consideración intelectiva» (SE 8) ${ }^{11}$. Pero, por otro lado, atribuye la distinción al principio creacionista inherente al cristianismo:

10 De hecho el Prologo al Evangelio de San Juan no es en modo alguno logicista. Al contrario, el misterio de Jesús es que en su realidad personal aúna el Logos ontológico y el Logos declarativo. Podrá o no creerse, pero esto es lo que se afirma.

11 Las referencias de Zubiri a este error son constantes a lo largo de toda su obra y a lo largo de Sobre la Esencia de principio a fin. Son la base de los límites atribuidos al principio de contradicción: (SE 67) «para aplicar el principio de contradicción necesito acotar una realidad y considerarla por sí misma; sólo así puede ser sujeto de atribución de un logos predicativo (...) pero in re este sujeto no está acotado respecto de los demás». Cuando más adelante rechaza la teoría clásica de la esencia como quiddidad, vuelve a sentenciar: (SE 218) «La insuficiencia del punto de vista predicativo estriba, pues, como primera razón, en ser un punto de vista que no se basta a sí mismo ni tan siquiera en su propia línea, porque depende de algo previo, a saber, el punto de vista físico». Y en la última parte del libro (SE 347): "[este "logos", el predicativo] tiene, cuando menos, tres limitaciones: la identificación del logos esencial con la definición; la identificación de todo logos con el logos predicativo y la identificación del sujeto del logos con una realidad subjetual». 
(SE 9) «de hecho, históricamente sólo la idea de la creación ex nihilo es la que ha conducido a la contraposición de essentia y existentia». El asunto se resuelve porque ambos postulados se subordinan a uno principal: que el error de la filosofía se produce por no «ir a las cosas físicas mismas» y adoptar, en cambio, una actitud «idealista» consistente en proyectar ideas sobre la realidad. Que las ideas se proyecten desde la revelación o desde una posición logicista no impide que sean a la postre sino modalidades de dicha actitud idealista. Zubiri era católico y obviamente creía en la verdad revelada en Jesucristo, pero su posición es que a la hora de hacer filosofía hay que ejercitar la razón en sí misma, es decir, ir a las cosas mismas, pues si no se corre el peligro de proyectar meramente ideas sobre la realidad y de este modo de carecer de agudeza también para interpretar la revelación. No dice, pues, como Heidegger, que la filosofía cristiana haya pervertido u ocultado el pensamiento griego, sino que lo que afirma es que no fue una verdadera filosofía: filosofía pura. La filosofía pura ha de consistir en «ir a las cosas mismas», que es, como es sabido, el leitmotiv de la fenomenología de Husserl, el problema es que Zubiri pensaba que el filósofo alemán no consiguió acceder verdaderamente a las cosas mismas por no lograr deshacerse completamente del influjo idealista de la tradición occidental.

La cuestión pivota, pues, en gran medida, sobre qué sea idealismo. En el sentido anunciado, todas las teorías de la esencia habidas — desde la platónica y aristotélica, pasando por la escolástica, el racionalismo moderno, Hegel y Husserl- habrían adolecido de idealismo de uno u otro modo. El idealismo, dice Zubiri:

(SE 49-50) «no es tan sólo, como tantas veces ha solido decirse, la afirmación de que el ser absoluto y radical es una inteligencia, sino (/) que el idealismo consiste en afirmar, además, que todo lo inteligido en y por esa inteligencia es tan sólo un momento formalmente inmanente e idéntico a la inteligencia misma, un contenido de ésta meramente pensado, sin más realidad formal y terminal que la pura intelección. Esto es, el idealismo consiste en afirmar que la inteligencia infinita es no sólo la realidad absoluta y radical, sino la realidad "físicamente" única. Y esto es imposible»

Es decir, el idealismo consiste en atribuir a la inteligencia en general, esto es, no sólo a las inteligencias finitas, sino a toda inteligencia, incluida la divina, una prioridad completa sobre todo, incluida la realidad sensu stricto. "Aún en el caso de Dios — afirma Zubiri (SE 48), la mera objetividad — ciencia de simple inteligencia - reposa por lo menos sobre una "previa" fecundidad "física" de la realidad divina». Todas las filosofías y sus correspondientes teorías de la esencia revisadas en el libro adolecen de idealismo. Husserl incurre en idealismo, porque su afán de lograr una ciencia estricta le lleva a recortar en la experiencia de lo real aquello que se deja aprehender absolutamente; es decir, renuncia a la verdadera alteridad de lo real, a la fuerza, al exceso de lo real, i. e., a lo 
trascendental; y ello es así con la finalidad de lograr verdades absolutas ${ }^{12}$. En esta línea, la reducción fenomenológica se identificaría con la reducción eidética de manera que la esencia de la cosa real es reducida a unidad eidética de sentido $^{13}$. El idealismo iría siempre de la mano de una cierta actitud de soberbia. El afán de verdades absolutas en Husserl sería el síntoma de esta soberbia. Frente a él, el realismo profesaría la humildad de inclinar la inteligencia ante las cosas, para ver qué es lo que ellas nos revelan.

Este punto es decisivo, porque aquí arraiga el debate. ¿Es capaz el hombre de verdades absolutas? ¿Es capaz la inteligencia humana, que necesariamente se despliega en el logos conceptual, de aprender absolutamente momentos de la realidad de las cosas? ¿U opera más bien en una esfera re-presentativa y derivada, que, mediándolas, de algún modo encubre y disfraza la realidad de las cosas (apariencia)? En términos de Heidegger, ¿es posible superar el lenguaje desgastado e impropio y acceder a un lenguaje originario que da palabra a las

12 SE 27: «Husserl parte, en efecto, de las leyes o necesidades absolutas. Dicho así lo obvio sería inclinarse sobre las cosas para ver de lograr penosamente el momento absoluto de ellas sin estar jamás seguros de alcanzarlo (...) Husserl no va directamente a las cosas, porque lo que quiere en primera línea es evidencias apodícticas, esto es, un saber que por su propia índole en cuanto forma de saber, garantizara esas evidencias y fuera, por tanto, un saber absoluto en y por sí mismo, a diferencia de todo saber La diferencia radical de que Husserl parte en toda su filosofía es la contraposición entre saber absoluto y saber empírico. No es la diferencia de dos modos de ser - lo absoluto y lo relativo- sino de dos modos de saber. Subsume, pues, el concepto de esencia bajo el concepto de absoluto, y a su vez hace de lo absoluto un modo de saber, con lo cual, en lugar de buscar lo absoluto de las cosas, lo que hace es acotar dentro de éstas aquella zona a la que alcanza ese saber, absoluto por sí mismo. En su virtud, Husserl ha lanzado el problema de la esencia por la vía del saber, es decir, por la vía del acto de conciencia en que la aprehendo. Pero con ello la esencia de las cosas queda irremediablemente perdida de antemano y jamás podrá volver a recuperarse [... lo que hace Husserl es] llamar absoluto a aquello de que hay conciencia absoluta (...) Al desviarse de las cosas y dirigirse a la conciencia en beneficio de un saber absoluto Husserl ha perdido, en el enfoque mismo de la cuestión, lo esencial de la realidad».

13 La reducción fenomenológica es descrita por Zubiri en: Zubiri (2007), Cinco lecciones de filosofía. Madrid: Alianza Editorial, p. 217; y Zubiri (2012), Sobre la esencia, op. cit., pp. 2526. Como la base de la crítica a Husserl es su idealismo en el sentido expuesto, aunque dicha crítica está pensada sobre todo para el Husserl de las Investigaciones lógicas, puede extenderse a la reducción trascendental de después de las Lecciones del Semestre de verano de 1905 sobre la Idea de la fenomenología (Ed. Husserl (2012), La Idea de la fenomenología. Madrid: Herder). El problema sería la amputación de la dominancia y el exceso del "de suyo", de la realidad, sobre la conciencia. Agustín Serrano de Haro ha puesto de manifiesto los límites de la crítica de Zubiri a la reducción husserliana al identificar la reducción trascendental con la reducción eidética (conferencia en el reciente congreso: IV Congreso Internacional sobre Xavier Zubiri, «Zubiri en el horizonte del Siglo xxı», celebrado en Morelia, Universidad Michoacana de San Nicolás de Hidalgo, Instituto de Investigaciones Filosóficas «Luis Villoro», Facultad de Filosofía «Samuel Ramos» y Fundación X. Zubiri de Madrid; Morelia, México, los días 27, 28 y 29 de agosto del 2014; Serrano de Haro, A., "Zubiri ante la fenomenología. Una visión desde Husserl» - las actas están en proceso de publicación-). Sin embargo, estos límites no anulan quizá el desacuerdo de fondo: la irreductibilidad de la realidad a conciencia, tal y como subraya Zubiri. 
cosas? O en términos de Parménides, ¿le cabe al hombre abandonar la vía de la opinión y acceder a la vía de la verdad, aunque ello fuere difícil o, incluso, muy difícil?

Al interpretar Zubiri la reducción fenomenológica como reducción eidética mediante la puesta entre paréntesis de la existencia para quedarse con la pura esencia, el pensador español sitúa a Husserl en la línea de la metafísica clásica y su distinción fundamental entre esencia y existencia. La verdad es que esta línea interpretativa es muy sugerente, al menos en lo que al Husserl de las Investigaciones lógicas respecta, pues en esta obra el pensador alemán era muy deudor de la tradición racionalista moderna leibnizina a través de Bolzano, y con ésta, de la tradición conceptualista escolástica ${ }^{14}$. En esta tradición los conceptos son el precipitado en la inteligencia humana de todo el proceso abstractivo. Este proceso permite a la inteligencia acceder a la esfera de lo universal, de las esencias puras, que vendrían a coincidir con el contenido eidético de las ideas divinas, el cual trazaría los límites de lo posible. Esta concepción, eminentemente representada por Suárez en el siglo XVII, llega hasta el Wittgenstein del Tractatus, en el que lo lógico (el espacio lógico) representa los límites de lo posible.

Parece un rasgo definitorio de la tendencia general del pensamiento contemporáneo — al menos desde luego a partir del siglo XIX — la convicción de que lo universal no es real, es decir, de que el contenido de los conceptos no refiere a nada real al margen de los contenidos concretos de las cosas individuales, únicas verdaderamente reales y a partir de las cuales dichos conceptos han sido abstraídos. Cualquier tratamiento del contenido de los conceptos como si fuera algo, como si las meras posibilidades ideales fueran ya "algo" apto para existir, es conceptismo: una sustantivación del contenido de los conceptos como si fuera algún tipo de realidad al margen de las cosas reales concretas de las que ellos han sido abstraídos. Ya hemos visto que Heidegger niega, junto a Nietzsche, esta hipóstasis, y Zubiri hace otro tanto. A este respecto el pensador español emprende una doble tarea. Por un lado, al elaborar su propia teoría de la esencia establece con toda rotundidad que sólo lo individual es real: (SE 137) «no hay nada real que no sea individual»; (SE 166) «no existe un "principio" físico de individuación, sino que toda sustantividad es individual no sólo en sí misma (...) sino por sí misma, esto es, por toda su realidad sustantiva: toda su realidad sustantiva es formalmente "esta"». Por otro lado, este rechazo de cualquier forma de realismo de los universales va acompañado de una crítica de las teorías clásicas de la abstracción, desde Platón hasta Husserl, y a la vez de una tarea constructiva en la que el pensador español reconstruye en su noología una teoría propia del concepto como un rendimiento del dinamismo del logos

14 Prieto, L. (2013), Suárez y el destino de la metafísica. De Avicena a Heidegger. Madrid: BAC. El autor analiza con gran agudeza el giro conceptualista que Suárez imprime a la metafísica y que marcará de forma decisiva el pensamiento moderno posterior en la línea en la habla Zubiri. Las esencias no serían pura potencialidad sino que gozarían de alguna entidad en la que se apoyaría su aptitud para existir. 
como modo ulterior de la inteligencia en el que ya interveniene la libertad. Hemos visto que Heidegger no va tan lejos. Se limita a constatar que el lenguaje por su propia naturaleza puede convertirse en un instrumento hipostasiado de la experiencia originaria (y por tanto encubridor de la realidad) y a hacer también una crítica de la abstracción en una línea similar, pues al construir el concepto, el carácter abstracto y rígido de éste, conllevaría apartar inexorablemente la mirada de la realidad concreta a partir de la cual se ha construido. Zubiri intenta afinar más y entra en un terreno extremadamente difícil.

\subsection{La crítica de Zubiri a las teorías clásicas de la abstracción}

El presupuesto de la crítica zubiriana es, como ya he señalado, la tesis de que no hay nada real que no sea individual, a la vez que una redefinición de la individualidad. La individualidad no es la determinación concreta de una especie última. Ello supone partir de los contenidos universales (sean géneros o especies) e ir descendiendo hasta la concreción de los individuos, que serían como realizaciones de la especie en cuestión. Este es un proceder de suyo idealista, pues va de las ideas (de los conceptos) a las realidades concretas. El proceder adecuado sería, empero, el contrario. Lo adecuado es partir de las realidades concretas aprehendidas en la aprehensión primordial sentiente y tratar de ver en ellas el momento esencial o, en su caso, específico, que las estructura realmente. Entonces la inteligencia nos descubre que hay tres momentos de individualidad en las cosas: 1) la individualidad numérica o singulum;2) la individualidad constitutiva; y en el caso de la sustantividad abierta humana, 3) la individualidad como concreción a través de posibilidades apropiadas; la libertad, optando, va determinando y concretando la figura histórica de la persona (personalidad), proceso que sólo se cierra con la muerte. El momento radical de la individualidad para Zubiri es la «constitución», porque aunque en un principio pudiera parecer que es la estricta individualidad numérica, a la postre no hay individuo sin constitución, por muy precaria que ésta sea.

(SE 137-138) «la constitución es algo estrictamente "individual”. Individual, ante todo, "en sí misma”, esto es, porque no hay nada real que no sea individual (...) Pero individual además "por sí misma”, y no algo meramente individualizado. La individuación, en efecto, no es un "principio" especial dentro de la realidad de la cosa (/) sino un simple "momento" de ella, aquel momento según el cual la cosa es esa unidad física irreducible por la que decimos, por ejemplo, que este hombre es formalmente "este". Ser "este" es ser formalmente una unidad física irreducible».

Zubiri califica la concepción clásica de la individualidad de «formalista y meramente negativa»: (SE 138) «Formalista, porque se mueve exclusivamente en la línea de la multiplicidad de lo "uno" y de lo "otro" sin atender a la índole de esta unidad. Negativa, porque se centra en la idea de la "indivisión", lo cual termina por formalizar al puro "uno"». Frente a ella introduce Zubiri su noción de la individualidad numérica: 
«Utilizaremos esta palabra "individualidad”, para designar aquel carácter de toda realidad según el cual esta realidad no es físicamente la otra (...) la realidad cuya individualidad consiste en ser una unidad meramente numeral (...de manera que) en no ser otro se agota toda su individualidad (...) Por razón de su contenido, pues, estos individuos son exacta y exhaustivamente iguales; se distinguen tan sólo por formar una mera multiplicidad numérica. A este tipo de individuo llamaré un singulum»

De todas maneras el singulum es sólo un caso límite inexistente en la realidad, pues todo lo que es real tiene que tener necesariamente algún grado de constitución, es decir, de unidad esencial de contenido: (SE 141) «en rigor, a estos individuos singulares puede aplicarse también el concepto de constitución (...) pero su constitución se reduce a la posesión de caracteres mínimos, exacta y exhaustivamente repetidos en todos esos singuli». Si cualquier realidad tiene algún grado de constitución, no habrá, como digo, realidades individuales sólo numéricamente, porque, justamente, el momento de individualidad numérica (que vendría dado por la formalidad de realidad, que es más originario que la materia y el tiempo) y el momento de constitución son momentos inseparables de la individualidad de la cosa:

(SE 140) «Pero no se trata de dos unidades, sino de dos aspectos de una sola unidad intrínsecamente única: la unidad de contenido modela o modifica el carácter de la unidad numeral. A esta modulación es a lo que llamo determinación interna (...) la unidad numeral así modulada o determinada es lo que entiendo por constitución: es el modo propio que cada cosa tiene de ser "esta". La unidad llega a ser numeral gracias precisamente a la constitución, y no al revés» ${ }^{15}$.

En la teoría clásica, tendríamos la unidad esencial de contenido (quidditas, especie ideal o unidad eidética), que después se individúa. En Zubiri, en cambio, la esencia y la individualidad se co-determinan mutua e inseparablemente: no hay esencia fuera de la individualidad, ni individuo sin esencia. Lo que individua es la constitución esencial, el momento unitario de clausura sistemática de las notas-de, porque formalidad física (individualidad numérica: función talitativa) y talidad (constitución: función trascendental) son inseparables. La cosa brota (concepto griego de physis sobre el que Heidegger nos llama la atención) como lo que es constitutivamente en la formalidad de realidad. Este brotar para nosotros, que somos quienes actualizamos intelectivamente lo real, es simultáneamente físico e intelectivo (es la co-actualidad noergica). Así, pues, la individualidad no es un «caer» en la individualidad desde la generalidad de la especie como en el esquema del árbol de Porfirio ${ }^{16}$.

15 En el mismo sentido, (SE 166): «no existe un "principio" físico de individuación, sino que toda sustantividad es individual no sólo en sí misma (...) sino por sí misma, esto es, por toda su realidad sustantiva: toda su realidad sustantiva es formalmente "esta". Ser "esta" significa que la autonomía y plenitud total de la sustantividad es una unidad suficiente e irreducible».

16 SE 166: «No hay contracción de la especie, sino expansión del individuo» 
A este respecto existe un segundo concepto de singulum, que en principio sí sería posible en la realidad y sobre el que Zubiri montará su concepto de clase natural. En un primer sentido ya hemos visto que singulum se referiría a una realidad con mera individualidad numérica; y hemos dicho que es un concepto límite imposible de hecho en la realidad. Pero en un segundo sentido singulum es una realidad con individualidad constitucional que es «prácticamente» idéntica desde el punto de vista de su esencia a otras realidades individuales con las que forma mera clase natural, es decir, que no se generan entre sí como es el caso en las especies («especie» en Zubiri tiene un sentido biológico: forman especie aquellos individuos que tienen en su esencia un subsistema generativo de otros individuos, un subsistema replicativo). Decimos que los singuli tienen una esencia "prácticamente» idéntica, porque también es de hecho un caso límite. Zubiri dice a este respecto:

(SE 167) «Toda individualidad, por ser una unidad internamente determinada, es determinadamente irrepetible, al paso que las singularidades son numéricamente multiplicables. Claro está que, de potentia absoluta, Dios podría hacer dos verdaderos individuos exactamente iguales sin que dejaran de ser dos (...) aunque fueran indiscernibles (...) pero es una mera posibilidad especulativa, de hecho no acontece así»

Es decir, en última instancia, aunque la esencia de dos individuos sea «prácticamente» la misma, es sólo prácticamente la misma, es decir, son muy parecidas pero no idénticas, pues toda esencia es en última instancia estrictamente individual $^{17}$.

La crítica a la teoría clásica de la abstracción la expone Zubiri sobre todo a partir de la página 216. El contenido abstracto del concepto lo mentaría el alma intelectiva en la teoría clásica a partir de la "visión» en las imágenes individuales de la identidad universal reflejada en el «mínimo de coincidencia»:

(SE 216) «[se trata] de un predicado mínimo tal, que entre él y el resto de los predicados individualmente atribuibles no quepa intermedio ninguno (...), es mínimo porque no envuelve notas y momentos individuantes; pero es máximo en la línea de la coincidencia pre-individual. Es un predicado último (...) y este mínimo y último predicado intrínseco es el eidos, عĩos, la especie... el quid de la cosa... esencia sería quidditas, quididad [... es, pues,] aquel punto en que una nueva nota ... reduce el género a una sola especie [... así] tendremos ya el eidos; esto es, algo en que ya no cabe más división...: el eidos

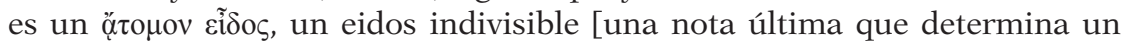
cambio de especie]. Ultimidad sería concretamente "indivisibilidad" natural del eidos. En esta concepción cada nota es un "divisor" que escinde las dos partes del dividendo, llevándonos a una [la especie] y separándonos de la otra [el género]; es una dia-fora/, diferencia. Toda diferencia tiene en esta concepción un carácter concreto; ser "divisor". Por tanto, toda diferencia esencial es diferencia quidditativa, diferencia específica (... de donde resulta que) diferencia esencial es diferencia de especie»

17 SE 213-214. 
Y unas páginas más adelante, continúa:

(SE 218) «todo ello pende (...) del punto de vista predicativo. La esencia sería minimidad de coincidencia y ultimidad de indivisión; la diferencia esencial sería un "divisor" y, por tanto, significaría diferencia de esencia. Ahora bien, esto no es satisfactorio por dos razones. En primer lugar, porque la predicación se apoya sobre algo ante-predicativo. Predicativamente la esencia no está unívocamente determinada»

Efectivamente, Zubiri se mueve fundamentalmente en el plano de individuos que son complejos (sistemas clausurados de notas-de), y no en el de notas simples. Cuando se tata de individuos complejos, efectivamente hay muchas líneas de determinaciones en las que se podría buscar la diferencia específica en el sentido de la concepción clásica de la definición esencial. En el caso del hombre se podría haber ido por la línea de la bipedestación y no de la racionalidad, por ejemplo. Lo que determina la vía elegida es, según Zubiri, un presupuesto previo: el quiditativo.

(SE 218) «No se busca simplemente "aquello en que todos coinciden, sino (...) aquello en que necesariamente han de coincidir si han de ser quidditativamente iguales. Lo cual significa que previamente a toda predicación se

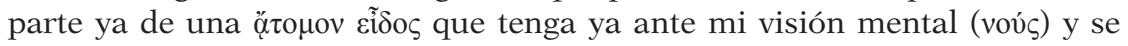
buscan después sus coyunturas naturales (...) Se parte ya de que el hombre es animal y racional, y después, sólo después, se hace de la racionalidad la última diferencia específica. Ahora bien, esto es abandonar la vía predicativa y dar rango primario a la realidad física»

Es decir, tal y como se plantea aquí, el problema no es tanto que haya realmente, es decir, físicamente, «diferencias» coincidentes en los individuos (por ejemplo, un determinado matiz de amarillo), sino que se pre-juzga cual es la diferencia esencial; es decir, hay «logocentrismo», anteposición del logos a la aprehensión primordial, uso «lógico de la inteligencia», y en este sentido, idealismo: predominio de la «voluntad de ideas» sobre la «voluntad de verdad». Pero creo que esto no supone una caída de la «teoría tradicional» de los universales, al menos no completamente, porque sí es verdad que puede haber un peligro de «conceptismo»:

«No se trata — sigue aguzando Zubiri la crítica—, como ya algún escolástico pretendió, de ampliar el ámbito de la predicación quidditativa con predicados individuales [este sería el caso de las notas simples al que yo acabo de aludir], sino de abandonar toda predicación para ir a la cosa en su realidad física y averiguar lo que en ella le confiere su minimidad y (...) La insuficiencia del punto de vista predicativo estriba, pues, como primera razón, en ser un punto de vista que no se basta a sí mismo ni tan siquiera en su propia línea, porque depende de algo previo, a saber, del punto de vista físico»

Nos encontramos aquí con una crítica similar a la que Heidegger esgrimía. Es como si la estructura del proceso abstractivo, que vendría condicionado por la estructura del logos predicativo, obligara a la inteligencia a abandonar el suelo de la experiencia originaria para mentar la identidad eidética, y en ese 
caso la inteligencia reposaría sola desgajada de la realidad en lo que Heidegger denominaba «conceptos carcasa». Pero me parece que en todo caso, aun si fuera así, se da una permanente dialéctica de vuelta del concepto al contenido real intuitivo donde éste se verifica (o no). El lenguaje no necesariamente se anquilosa.

La crítica da un paso más en la página 229. Para la teoría clásica de la abstracción, y en ella iría incluida la ideación de Husserl, toda realidad individual sería (por abstracción o ideación) especiable. Y contra ello argumenta Zubiri lo siguiente:

«esto es imposible. En primer lugar, esto que Husserl llama especie presupone una disociación entre "este" rojo y "lo" rojo [la rojez]. En segundo lugar, "lo" (rojo) es algo ideal, pero cuya idealidad tiene una precisa estructura: unidad de identidad. Reaparece aquí el viejo tema platónico y aristotélico del

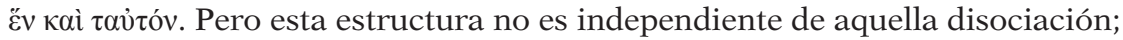
sólo en la medida en que hay disociación hay idealización. Ahora bien, no es evidente a priori — sigue argumentado Zubiri- que cualquier realidad sea susceptible de tal disociación. Una cosa real que por su propia índole fuera única no admitiría la disociación entre "este" y "lo"; para ello es menester que haya varios individuos»

¡He aquí la cuestión crucial! ¿Tiene razón Zubiri? No estoy seguro, pero en principio diría que no. Lo decisivo es que esa cosa, aunque sea única, esté determinada, caracterizada o di-ferenciada (no digo "talificada», porque ello implica constitución y ahora estamos hablando de notas simples). Si está determinada, entonces la inteligencia sentiente creo que podrá disociar o desgajar el "lo": la idealidad, de la concreción individual de la cosa. En primer lugar, porque toda determinación, aunque fuere única podrá disociarse de otras determinaciones di-ferentes, con lo que la inteligencia caerá en la cuenta de su peculiar diferencia, es decir, de la identidad de su diferencia. Y, en tal caso, aunque la determinación sea única, ¿no habrá captado ya la inteligencia el "lo” repetible de dicho contenido, aunque de hecho no se repita ni pueda repetirse en este mundo (¿mundo? ¿cosmos?)? Es verdad que en Husserl (Segunda Investigación Lógica) la abstracción tiene lugar captando la identidad de las determinaciones iguales en múltiples individuos, pero, como digo, no estoy seguro de que esta multiplicidad sea necesaria. Se requiere, eso sí (y esto es fundamental para contrastar la capacidad metafísica del logos humano con la hipótesis hermenéutica, que le niega la capacidad de acceso intuitivo a lo real), un dinamismo del logos para captar la diferencia, es decir, para desvelar la determinación en sí misma, rompiendo la compacidad de la aprehensión primordial. Este dinamismo originario, que es la esencia del logos sentiente, no lo es primariamente entre la cosa (la nota) y una simple aprehensión o idea —pues en el origen no hay ideas-, sino que lo es entre dos cosas di-ferentes o iguales. De hecho la esencia del logos en términos zubirianos es «inteligir una cosa entre otras», es decir, inteligir una cosa en la campo de realidad. En este sentido, la mediación campal del logos, no es una mediación que de algún modo vele (oculte) el contenido de la cosa real añadiéndole capas de sentido, sino que es una mediación 
lumínica que lo único que hace es sacar a la cosa de la penumbra propia de la compacidad de la aprehensión primordial en que originariamente se da. Son justamente las «otras» cosas entre las que se intelige la cosa en cuestión las que arrojan luz sobre ella actualizando su diferencia real. Como la realidad es campal, por muy única que sea una cosa remite necesariamente a la inteligencia a inteligirla entre otras. Una vez captada la nota (la diferencia), ello implica necesariamente una permanencia en su identidad; si no no podría ser distinguida. Este es el momento sustancial inexorable en la realidad. Evidentemente, no se

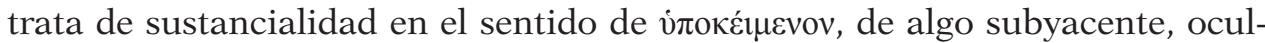
to, sino en el sentido de algo físico que se sostiene en la presencia al menos un tiempo. Y sobre esta base, ¿no se produce necesariamente la disociación entre «esta» determinación y «la» determinación genérica como عĩoos?

Es verdad que lo que lleva a la inteligencia a postular la «realidad» de lo ideal parte de la multiplicidad de determinaciones comunes. Que haya dos individuos del mismo matiz de color exige que haya algo eidético que trasciende la estricta individualidad. La metafísica clásica desde Platón, en la medida en que identificaba el principio de individuación con la materia, defendía la necesidad de la «existencia» (en algún sentido de existencia) de los universales. Si la materia es incomunicable, estrictamente individual, (mi carne es sólo mi carne, etc.) lo que hace iguales a individuos distintos deberá transcender dicha materia. Si esta ventana es blanca y esta otra es igualmente blanca, su carácter de blanco no podrá estar encerrado en la materialidad singular, sino que de alguna manera la trasciende, es capaz de determinar a múltiples individuos distintos. Si sólo hubiera un individuo, el nous humano no captaría esta peculiaridad de lo eidético, y entonces parece que como afirma Zubiri la multiplicidad es una condición necesaria para que nosotros nos percatemos de lo eidético. ¿Pero es, a caso, también condición necesaria de lo eidético mismo? En todo caso Zubiri hace frente también a esta objeción:

(SE 229) «Y la cosa es aun más clara si atendemos a la estructura de lo ideal, esto es, a la unidad de identidad. No se tata de una mera identidad objetiva, resultado de un acto noético, sino de una unidad cuyo término sea algo "físico", algo real. Ahora bien, en esta línea, la unidad de identidad se apoya en el momento común a una multitud de individuos frente a los cuales puede concebirse objetivamente aquella unidad de identidad... llegamos [pues] a la misma conclusión que por la disociación entre «este» y «lo»: el supuesto primario y radical de la especiación es la multitud física de individuos. Esta multitud no es sólo una condición para llegar de hecho al conocimiento de la especie, sino que es la condición intrínseca para que haya especie in re, esto es, para que haya especiación de una realidad sustantiva individual. Sólo hay especie cuando hay multitud unificable. Donde esto no acontece hay esencia física, pero no hay especie. Especie no es unidad ideal»

Y si se opta por una debilitación de la hipóstasis de las ideas en la forma de defender que: «La unidad de semejanza constituiría la especie. Aquí la especie no es algo meramente ideal, sino algo a su modo real (...) esto me parece igualmente insostenible [...porque] 1) se aplicaría igualmente a (...) las cosas 
artificiales, y, en general, a todas las «cosas-sentido», lo cual es inaceptable, porque estas cosas tiene concepto objetivo pero no tienen esencia y, por tanto, mal pueden tener especie».

Por fin, Zubiri atribuye a la «teoría tradicional» la confusión entre «especie» y clase».

Como se ve, el asunto es harto complejo, y yo creo que no se puede dar por zanjado en ningún sentido. La aprehensión de las identidades abstractas (universales) puede muy bien revelar estructuras formales de la realidad y ser la base de «ontologías regionales» así como de una «ontología formal» al modo de las apuntadas por Husserl en las Investigaciones lógicas. En mi opinión esto no es descartable según el estado actual de las cosas. Más investigaciones son aquí precisas. El enfoque de la Trilogía, como en general las diversas investigaciones sobre los procesos noéticos, son complementarios a estos análisis sobre los que aquí hemos reflexionado, pero no los sustituyen.

Universidad Eclesiástica San Dámaso

Víctor M. TiRado SAN JUAN

y Universidad Pontificia de Sañlamanca

vtirado@sandamaso.es

[Artículo aprobado para publicación en este número extraordinario en noviembre de 2014] 
